\title{
Genetics and biology of Anastrepha fraterculus: research supporting the use of the sterile insect technique (SIT) to control this pest in Argentina
}

\author{
Jorge L Cladera ${ }^{1 *}$, Juan C Vilardi ${ }^{2,3}$, Marianela Juri ${ }^{1,2}$, Laura E Paulin ${ }^{2,3}$, M Cecilia Giardini ${ }^{1}$, Paula V Gómez Cendra ${ }^{2,3}$,
} Diego F Segura', Silvia B Lanzavecchia ${ }^{1}$

\begin{abstract}
Two species of true fruit flies (taxonomic family Tephritidae) are considered pests of fruit and vegetable production in Argentina: the cosmopolitan Mediterranean fruit fly (Ceratitis capitata Wiedemann) and the new world South American fruit fly (Anastrepha fraterculus Wiedemann). The distribution of these two species in Argentina overlaps north of the capital, Buenos Aires. Regarding the control of these two pests, the varied geographical fruit producing regions in Argentina are in different fly control situations. One part is under a programme using the sterile insect technique (SIT) for the eradication of C. capitata, because A. fraterculus is not present in this area. The application of the SIT to control $C$. capitata north of the present line with the possibility of $A$. fraterculus occupying the niche left vacant by $C$. capitata becomes a cause of much concern. Only initial steps have been taken to investigate the genetics and biology of $A$. fraterculus. Consequently, only fragmentary information has been recorded in the literature regarding the use of SIT to control this species. For these reasons, the research to develop a SIT protocol to control A. fraterculus is greatly needed. In recent years, research groups have been building a network in Argentina in order to address particular aspects of the development of the SIT for Anastrepha fraterculus. The problems being addressed by these groups include improvement of artificial diets, facilitation of insect mass rearing, radiation doses and conditions for insect sterilisation, basic knowledge supporting the development of males-only strains, reduction of male maturation time to facilitate releases, identification and isolation of chemical communication signals, and a good deal of population genetic studies. This paper is the product of a concerted effort to gather all this knowledge scattered in numerous and often hard-toaccess reports and papers and summarize their basic conclusions in a single publication.
\end{abstract}

\section{Background}

Two species of true fruit flies (taxonomic family Tephritidae) are considered pests of many fruits and vegetables in Argentina: the cosmopolitan and well known Mediterranean fruit fly (Ceratitis capitata Wiedemann), and the less conspicuous South American fruit fly (Anastrepha fraterculus Wiedemann). In this country the distribution of these two species overlaps from north of San Juan Province (parallels $30 / 31^{\circ} \mathrm{S}$ ), in the extreme west, to the north part of Buenos Aires Province (parallels $34 / 35^{\circ} \mathrm{S}$ ) in the east, and extends all the way to the northern

\footnotetext{
* Correspondence: cladera.jorge@inta.gob.ar

'Instituto Genética EA Favret, Instituto Nacional Tecnología Agropecuaria,

1686 Hurlingham, Provincia Buenos Aires, Argentina Full list of author information is available at the end of the article
}

border of Argentina. A. fraterculus is particularly present in the subtropical north-east (NEA) and north-west (NOA) regions [1], where the weather is warm and humid. These two regions are separated by the bio-geographical province of Chaco [2], a very arid region where A. fraterculus is normally absent (see references in: [3-5]).

Regarding the control of these two pests, the varied geographical fruit-producing regions in Argentina involve quite different situations. Patagonia and southern Cuyo are fruit fly free areas. Northern Cuyo (where A. fraterculus is not present) is under a pest management programme using the sterile insect technique (SIT) for the eradication of C. capitata. The main strategy to deal with the fruit fly problem in NOA is to follow quarantine protocols for the export of fruit (mainly
C Biomed Central 
lemon), whereas in NEA chemical control is applied and monitoring records are kept for both pests.

Ceratitis capitata is thoroughly known because of its wide prevalence in many places of the world. Regrettably, only initial steps have been taken to investigate the genetics and biology of $A$. fraterculus. As a consequence, a well-established protocol is available for the application of the SIT as a control method for C. capitata, but only fragmentary information has been recorded in the literature regarding the use of the SIT to control A. fraterculus. For this reason, research to develop a SIT protocol to control $A$. fraterculus is greatly needed.

In recent years, a research network has been building up in Argentina in order to address particular aspects of the development of the SIT for $A$. fraterculus. Besides two groups at Instituto Nacional de Tecnología Agropecuaria (INTA) in Castelar, Buenos Aires, scientific and technical studies are underway at the Universities of Buenos Aires (UBA) and Tucumán (UNT), the EEAOC (Estación Experimental Agroindustrial Obispo Colombres) in Tucumán, INTA Experimental Stations in Concordia (Entre Ríos) and San Pedro (Buenos Aires), besides laboratories at CNEA (Comisión Nacional de Energía Atómica) in Ezeiza (Buenos Aires) and from Instituto de Investigaciones Bioquímicas de Buenos Aires (IIBBA, Consejo Nacional de Investigaciones Científicas y Técnicas), and Planta Piloto de Procesos Industriales Microbiológicos (PROIMI, Consejo Nacional de Investigaciones Científicas y Técnicas) in Tucumán.

The problems being addressed by these groups include improvement of artificial diets and mass rearing, radiation doses and conditions for insect sterilisation, basic genetic knowledge supporting the development of malesonly strains, reduction of male maturation time to facilitate releases, identification and isolation of chemical communication signals and population genetic studies. This paper is the product of a concerted effort to gather all this knowledge scattered in numerous, relatively inaccessible reports and papers and summarize their basic conclusions in one publication.

\section{Anastrepha fraterculus}

The nominal species $A$. fraterculus, is a highly polyphagous pest reported to occur from southern United States (Texas) to Argentina [6,7], attacking over 80 species of plants along this range, including major fruit crops $[8,9]$. Its presence limits international trade because of quarantine regulations to avoid cross-border introductions [7]. This pest and C. capitata are the only fruit fly species of economic and quarantine importance reported in Argentina. These species are also economically important in large fruit production areas of Peru, Uruguay, and southern Brazil (see $[10,11]$ and the present review). The development of technologies and strategies for control and/or eradication of both species simultaneously is of great interest. Furthermore, the application of the SIT to control C. capitata in overlapping areas with the possibility of $A$. fraterculus occupying the niche left vacant by C. capitata becomes a cause of much concern. Any effort to remove, suppress or exclude $A$. fraterculus from fruit producing regions should have a positive impact on local development and regional economies. In contrast, if no effective control method is developed against $A$. fraterculus in the near future, possible population expansions of this species might greatly reduce the benefits of $C$. capitata control in those areas of coexistence [10,11].

At present, the only control method available for A. fraterculus is the use of bait sprays. This represents a problem particularly in areas where it coexists with C. capitata. In such situations, the application of the SIT against $A$. fraterculus is a very attractive alternative ([11], see more ref. in [12]). At the South American regional level, research on the possibility of using the SIT to eradicate populations of $A$. fraterculus was initially reported in a workshop organised by the International Atomic Energy Agency (IAEA) at Viña del Mar in November 1996 [10], but prior to that, a number of investigations had already been advancing; especially at the University of São Paulo and Empresa Brasileira de Pesquisa Agropecuária (EMBRAPA), Rio Grande do Sul, in Brazil; and, in Argentina, at Instituto de Genética INTA, the University of Buenos Aires, and Centro de Investigaciones para la Regulación de Poblaciones de Organismos Nocivos (CIRPON-Tucumán) [6,13-16]. Furthermore, already in the 1970's, Peruvian researchers at La Molina facilities in Lima performed pioneering efforts in this direction producing a series of reports published in local journals [17]. However, a problem with this early research is that the taxonomic delimitation of the entities under analysis was not entirely clear.

In reference to the taxon $A$. fraterculus, many reports have compared flies from different sites or hosts (see references listed recently by Cáceres et al. [18]). Records show differences in morphology [19], karyotypes, isozymes [20], host preference [21], egg morphology [22], hybridisation [23], mitochondrial DNA [24], highly repetitive DNA [25], morphometrics [26], and mating compatibility [27]. Many authors have indicated that the nominal species, $A$. fraterculus, actually is a complex of species (for a first revision, see [7]; and for additional discussion, see $[26,28,29])$.

Resolution of this complex is of outmost importance. This problem is now being addressed by a multidisciplinary research project coordinated by FAO/IAEA. Specialists from Argentina, Brazil, Colombia, Czech Republic, Italy, Mexico, and USA met recently (August 2013) in Tucumán, Argentina, and agreed on the fact that $A$. fraterculus 
is composed of at least seven different biological entities: "Ongoing studies using different methodologies (DNA, morphology, cytology, sexual behaviour, and the chemical profile of male-emitted volatiles and cuticle extracts) confirm the existence of several of these species. This result is also supported by a comprehensive morphological study that incorporates collections from the whole region. Finally, a large number of mating crosses among various origins points towards the fact that the population differences are correlated with behavioural reproductive isolation. Research is ongoing to define species limits and their distribution, as well as to formally name these putative species. This will be critical for international trade and any SIT application (Insect and Pest Control Newsletter No82, January 2014, p.15). In fact, as mentioned by Silva and Barr [30], the delimitation and identification of a species or a complex of species is essential for basic and applied research and have far-reaching practical consequences, as is the SIT implementation. This characterisation needs to be achieved by studies about genetic, morphology and behaviour.

\section{Biology of Anastrepha fraterculus}

For an efficient and effective application of the SIT we need an adequate knowledge of the biology of the pest species in general, and of the potential target populations in particular. The successful application of the SIT requires the ability to rear, sterilise and distribute sufficient insects to achieve a high sterile-to-wild insect ratio in the field, and also that the sterile males can successfully compete and mate with their wild counterparts after being mass-produced in an artificial environment, exposed to ionising radiation, densely packed and shipped to a distant facility, often immobilised, chilled, and ejected from flying aircraft [31]. The key biological aspects that determine the suitability of laboratory strains for SIT have been identified as: colonisation procedures and strain management, especially studies on insect nutrition, irradiation protocols, field dispersal and survival, field cage behaviour, and mating compatibility and competitiveness [31]. For A. fraterculus some of these aspects have been reviewed by Cáceres et al. under the umbrella of "quality management" [32]. We review here some aspects on $A$. fraterculus biology that may be necessary to apply the SIT on this species.

The literature on life history strategies of tephritid fruit flies, reviewed by Fletcher [33], reports for A. fraterculus that adults do not disperse long distances, live 3-4 months in the laboratory, spend unfavourable periods in the adult stage, mate away from host plants, feed on ripe fruit and produce 200-400 eggs per female (citing works of Malavasi and Morgante [34], and Malavasi et al. [35]). In recent years, Utgés [36] has evaluated the dispersal and the spatial distribution of $A$. fraterculus, which had received different pre-release diets. The average maximum distance reached was 150-160 m (according to records obtained for up to 8 days after release) and no differences were found among diets or between sexes. Larger capture densities were always near the releasing point and there was no apparent association with wind direction. The oviposition behaviour of $A$. fraterculus was first observed by Barros et al. [37] who described that after landing on the fruit, the female displays three stages: searching, puncturing (egg-laying) and dragging of the ovipositor over the fruit surface. Prokopy et al. [38] showed that in the process of dragging her ovipositor, the female deposits on the fruit an "oviposition-deterring pheromone".

Although an A. fraterculus strain was artificially reared in Peru as early as 1971 [39], the first report of artificial rearing was published by Salles in 1992 for A. fraterculus from Brazil [13]. This author tested the influence of photoperiod [14] and temperature [15] on development, finding that the life cycle may be completed between 20 and $25{ }^{\circ} \mathrm{C}$, but largest amounts of eggs are laid at $25^{\circ} \mathrm{C}$. A more thorough work by Cardoso et al. [40] evaluated the effect of temperature on the reproductive potential, life span, and life expectancy. By 1996, four research groups (in Peru [41], Brazil [42], Argentina [43], and Colombia [44]) were rearing $A$. fraterculus and performing small scale experiments in laboratory. A preliminary protocol for mass rearing A. fraterculus in Argentina was first published by Jaldo et al. [45] and Vera et al. [12] improved this technique and tested quality control parameters on a medium size scale of production. The nutritional requirements of $A$. fraterculus comparing different diets containing sugar, protein or other nutrients, either simultaneously or alternating have been then extensively investigated [36,46-48]. The general conclusion is that adult flies are able to select the food according to their needs and, for rearing facilities, the strategy of offering sugar and protein in different feeders could lead to an optimal ratio in terms of maturation and survival.

The survival of laboratory-reared sterile insects must be investigated because, as mentioned above, the massrearing and sterilisation processes required by the SIT may cause loss of fitness [49-51]. Experiments in field cages performed in Argentina showed that laboratoryreared males (either irradiated or not) may have a similar or higher survival rate compared to wild ones [46]. Incidentally, survival in field cages is drastically shorter than under laboratory conditions [40,52]. This indicates that field cage represents a challenging environment simulating open field conditions useful for quality control tests for laboratory-reared males. The effect of nutrition on $A$. fraterculus survival in open field was also studied by Utgés [36]. A trend to a reduction in 
survival when adult flies had received a diet rich in protein was suggested; however, in open field experiments survival is inferred from trap captures (non-protein baits are not available for A. fraterculus yet), so the possibility that insects fed with proteins before release are less attracted to traps with protein baits cannot be ruled out as a potential bias in this study.

\section{Mating behaviour of Anastrepha fraterculus}

Aluja and Norrbom stated that "The success of the SIT hinges on a deep understanding of behavioural mechanisms" [53]. Among them, the ability of sterile males to mate and transfer functional sperm to wild females is one of the key factors. This ability depends on the processes of sexual maturation, the courtship behaviour and the ability of released sterile males to modulate re-mating behaviour in females. All three aspects were investigated in A. fraterculus and are briefly reviewed here.

A long pre-copulatory period of adult males poses a problem in the practice of the SIT. When sterile flies are maintained at the fly handling facilities for several days before their release, the operational costs (food, space, and staff cf. [54]) considerably increase. Besides, holding adults may also lead to physical damage to the flies (cf. [55]), sometimes forcing the release of sexually immature flies, which are not able to compete with wild males.

As for other Anastrepha species, in A. fraterculus, sexual maturation is a slow process, so the male maturation problem has received a good deal of attention. Lima et al. [52] reported that males reach complete sexual maturation 8-9 days after emergence, and Salles found that some males start pheromone calling (males expand the abdominal pleura, where the salivary glands are located [56]; see Figure 1) at day 5 after adult emergence [42,57]. More recently, Segura et al. [58] have found high variability in the age that males need to reach to exhibit the pheromone calling (Figure 1) and be able to mate; the average is approximately 7 days after emergence, but

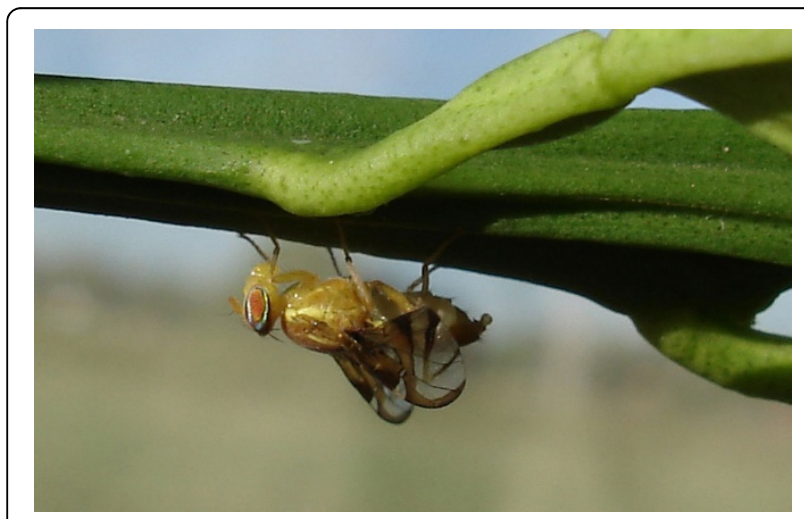

Figure 1 Male $\boldsymbol{A}$. fraterculus. Calling male expanding the abdominal pleura where the glands are located some males start to mate with virgin females at day 4 and others need 10 days. Some evidence of the genetic control of this variability was found studying mutant strains of $A$. fraterculus. The Sexual maturation process was significantly faster in one strain than in the others and this trait was paternally inherited [59].

The juvenile hormone analogue methoprene (applied topically) shortens in ca. 3 days the pre-copula period of sterile $A$. fraterculus males under laboratory conditions [58]. The mating competitiveness in field cages of young methoprene-treated males was found very satisfactory [60-62]. It has been also found that methoprene did not accelerate maturation in females to the same extent, so a sort of "physiological sexing" results as by-product, which may help to increase the efficiency of the SIT against A. fraterculus [61]. The age of first calling also varies in response to the adult diet [36], so the implementation of methoprene acceleration would also require that flies receive sugar and protein before they are released [60,61]. Methoprene-treated males induce in wild females less "refractoriness" to re-mate than mature wild males [62]. Probably the juvenile hormone analogue accelerates the mating onset in A. fraterculus males but does not act as efficiently in the synthesis of males' accessory glands products, which modulate females re-mating behaviour, a hypothesis that needs evaluation.

Once sexually mature, the $A$. fraterculus male engages in complex sexual behaviours that may become critical in deciding success or failure of the SIT released male insects attempting to mate with females in the wild. These behaviours include, besides the above mentioned pheromone calling, "lekking", acoustic signals, increased motion activity and wing displays. These activities as well as the effects of rearing conditions on them are briefly reviewed here.

Lekking: To attract females and mate, the males of some species aggregate in a group denominated lek. In A. fraterculus each lek is integrated by 3-8 males [35] who increase their mating probability by investing more time in calling [63]. Some males may be calling outside the lek or alternating inside and outside [35], however, males that call always inside the lek mate more frequently than the others [63]. This stresses the importance of calling location in male mating success.

Courtship: Mating in A. fraterculus takes place mostly on the abaxial surface of those leaves that are more exposed to sun light, where the lek is usually located $[35,64]$. The diel pattern of calling activities differs in flies from different geographical origin $[18,27,65]$. In populations studied by Malavasi and co-workers in Brazil $[35,64]$ and Petit-Marty et al. in Argentina [66,67], males start pheromone calling soon after sunrise and end before noon. The sequence of behaviours that leads to a successful mating was registered through video recordings by Gómez Cendra et al. [68]. Successful males 
generally reached copulation within 10 minutes after a female was in their proximity. Males that did not reach copulation exhibited some behavioural differences when compared with successful ones [68]. Vibratory cues produced during calling are also involved in A. fraterculus courtship. Differences in the calling song among different populations might also be related to the existence of prezygotic isolation barriers [64,69,70] (see below).

Chemical cues: $A$. fraterculus wild males attract females on the basis of chemical signals (sex pheromones), which may be important in mating success and compatibility between strains. The components of sex pheromones in extracts from salivary glands were studied by gas chromatography coupled with mass spectrometry [71]. These studies show that $A$. fraterculus pheromone is a complex mixture of several compounds that vary largely in their relative amounts. The role of each of these compounds in courtship remains to be assessed, but differences in chemical profiles among different populations have been used to postulate the existence of pre-zygotic isolation barriers [18,72].

Plant compounds: Plant compounds have been found to affect male courtship and, indirectly, male mating competitiveness in other Tephritidae species (cf. methyl-eugenol in some Bactrocera species or ginger root and orange essential oils in C. capitata [73]). Exposure to guava fruit volatiles does enhance male mating success in laboratory A. fraterculus [74]. This response has been suggested to be associated to $\alpha$-copaene, a compound that has been known to strongly improve mating success in $C$. capitata and is present in low amount in guava fruit, although other compounds might also be involved.

Sexual success: In the SIT the external morphology may be relevant to the mating success of released sterile males. Sciurano et al. [75] compared the multivariate phenotype between successful and unsuccessful males competing to copulate in caged trees ( see Figure 2). Specific traits, such as wing width and thorax length, were identified as most probable targets of sexual selection. Male mating success does not seem associated with size but rather to body shape. In fact, Segura et al. [63] found no relationship between body size and mating success or the ability of males to integrate into leks; however, the "face width" was found to be negatively associated to copula duration and positively associated with latency (the time between fly release into the cage and copulation), and the "eye length" was positively associated with copula duration and probability to mate. Artificial rearing may have a side effect on the multivariate phenotype of $A$. fraterculus. In general, lab flies are larger and show reduced variance in body size related traits compared to flies from the wild. Specifically, lab males have wider head, longer eye and narrower wing than wild males [5].

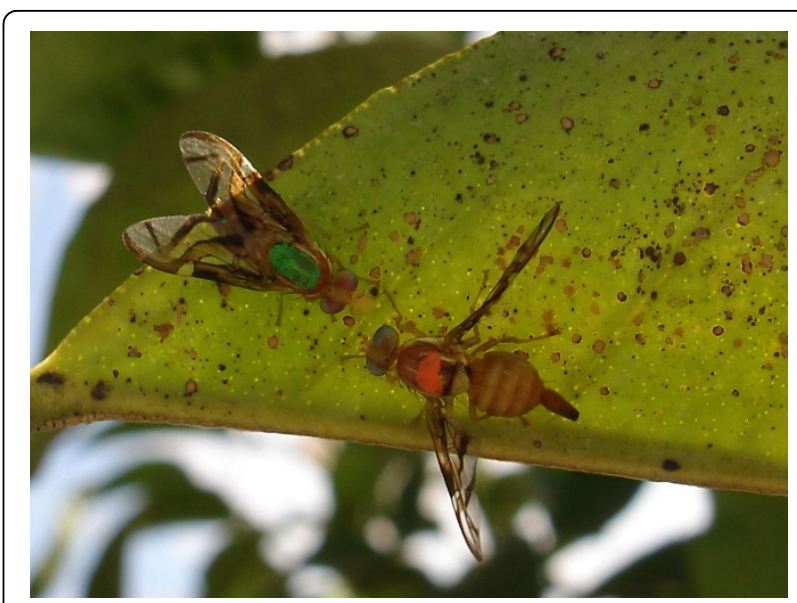

Figure 2 Female $\boldsymbol{A}$. fraterculus. Approaching a male in an attempt to copulate (dot of color paint on the thorax for identification of flies in a caged tree)

Re-mating: The female propensity to mate again after the first copula may be very relevant for the implementation of any SIT programme. The first record of $A$. fraterculus remating behaviour was performed by Lima et al. [52] in Brazil, but most studies on the frequency and other details of this phenomenon were conducted in Argentina by Abraham et al. [62,76-78]. The most important conclusions of this research are that a long-lasting first mating and a protein-rich male diet may reduce re-mating $[77,78]$ and that female re-mating propensity seems to be associated to sperm depletion [76]. The amount of sperm stored by females is not affected by male irradiation, methoprene treatment, or protein intake. Interestingly for the application of the SIT, A. fraterculus from Argentina has a refractory period so long (16 to 19 days respectively for laboratory and wild females) as to be considered a functionally non-re-mating species [76].

\section{Irradiation dose for male sterilisation}

The introduction of sterility in the females of the wild population is achieved following their mating with released males carrying dominant lethal mutations that have been induced in their sperm by radiation treatment [79]. The SIT can only be effective if the irradiated male is able to perform all the functions of a normal fertile insect, mainly it must carry fully functional sperm that succeeds in fertilising eggs and initiating their development [79]. Radiation biology studies are essential within the SIT framework [80]. In general, studies have focused on determining a radiation type (gamma or $\mathrm{X}$ ) and a dose that guarantees full sterility of flies with no detrimental effect on males ability to inseminate wild fertile females. Environmental conditions (temperature, humidity, oxygen concentration, etc.) as well as the developmental stage, at which irradiation is carried out, have been also addressed for many 
species (see [81]). Specifically for Tephritidae the average sterilisation dose reported (based on 21 species) was 63Gy [80].

In this context, we review now some studies dealing with the effect of ionising radiation on sterilisation and development of $A$. fraterculus. On the Peruvian population a dose of 50 Gy induces sterility on males [17]. Female sterility is induced with doses of $30 \mathrm{~Gy}$, but 60 Gy are needed to completely stop egg laying [17]. Allinghi et al. [82] showed that 60 Gy significantly reduce male fertility in flies from an Argentinian population, but complete male sterility requires a dose of $70 \mathrm{~Gy}$, irrespectively of the age at which pupae were irradiated. In this study, 40 Gy were enough to suppress egg-laying in females.

Allinghi $e t$ al. also performed standard mating competitiveness tests in outdoor field cages (cf. IAEA [83]) where laboratory $A$. fraterculus males that were irradiated $48 \mathrm{~h}$ prior to emergence competed with fertile wild flies [84]. They showed that irradiation affects neither the mating competitiveness of sterile males or females, nor the latency to mate. A mild effect of radiation was found on mating duration, as fertile flies mated for a significantly longer period of time. Males irradiated at 40 Gy produced incomplete sterility on wild fertile females, but at a dose of 70 Gy (or higher) more than $99.8 \%$ sterility is induced [84]. The protocol proposed by Allinghi et al. $[82,84]$ (gamma radiation at a dose of $70 \mathrm{~Gy}, 48 \mathrm{~h}$ preceding emergence) was further evaluated to test irradiation effects on other important aspects related to the effectiveness of the SIT. So far, radiation has shown no effect on survival [46], dispersal [36], sexual maturation [58], mating competitiveness after juvenile hormone treatment [60] or re-mating behaviour [62].

The effect of radiation on the development of the reproductive system of $A$. fraterculus was studied in male and female flies from Argentina [85]. Irradiated females showed a marked reduction on the growth rate of the ovaries, which turns evident by day 4 after emergence. On the other hand, testis size was not affected by irradiation; however, the organisation of the testis is noticeably affected: the growth zone is reduced in size, spermatids are difficult to detect and become round-shaped (losing their normal triangular shape), the zone where sperm remains as a bundle becomes larger and, concurrently, the zone with free sperm is smaller [85]. These findings have practical implications for the SIT because the differences in morphology and/or structure between sterile and fertile males can be used as a diagnostic tool to differentiate wild and mass-released laboratory male flies (when the fluorescent dye used to mark laboratory flies is not detectable). This diagnostic method arises as a by-product of sterilising flies with gamma radiation.

The current knowledge on radiation biology of $A$. fraterculus provides a good starting point for any control programme focused on this species. Nonetheless, the fact that the same radiation dose can affect flies in very different ways according to several biotic and abiotic parameters makes it reasonable to caution that assays, as those performed for the local morphotype in Argentina, should be replicated by other control programmes.

Another important venue of information that needs further research is the replacement of gamma irradiators by X-ray irradiators [86], as an alternative to deal with the difficulty to move radioisotopes across countries and the discontinuing in production of the Gamma Cell. (However, there are still some unsolved problems with $X$-ray irradiators: see IAEA Insect Pest Control Newsletter 81 , July 2013). In any case, experimental approaches like the one followed by Bachmann [87], in which gamma rays and $\mathrm{X}$-rays were compared will surely provide valuable information to support the future use of either type of ray.

\section{Chromosomes of Anastrepha fraterculus}

Chromosomal studies are important from different points of view. Cytological studies may provide critical information to identify cryptic species and detect polymorphisms, which may help to solve the A. fraterculus complex. A deep karyotypic analysis and a description of polytene chromosomes in Dipterans are valuable tools for identifying chromosome translocations (either spontaneous or induced) that can be used to develop genetic sexing strains.

The original description (1958) of chromosomes in $A$. fraterculus was performed by Mendes for a Brazilian population [88]. He reported that the chromosomal constitution of $A$. fraterculus is $10 \mathrm{~A}+\mathrm{XX}$ (females) and $10 \mathrm{~A}+$ $\mathrm{XY}$ (males), with terminal centromere localisations for all chromosomes, and somatic pairing between homologous [88]. In 1962, Bush studied the metaphase chromosomes of $A$. fraterculus from Mexico, where the heteromorphic (sex) chromosome pair was not present [89]. To explain the difference from Mendes result, Bush advanced the hypothesis that he was "more likely dealing with a sibling species" [89]. Later, in 1987, again in Brazil, Solferini and Morgante [90] confirmed the diploid number $(2 \mathrm{n}=12)$ and the distinction of $\mathrm{X}$ and $\mathrm{Y}$ sex chromosomes. Among the five pairs of acrocentric autosomes, one of them is described as "characteristically larger" than the others. These authors reported a polymorphism concerning the sex chromosomes and concluded that some of the morphs represent members of a complex of cryptic species. Also in Brazil, in 1996, Selivon [91] separated samples of A. fraterculus from different places and hosts in two groups according to their isozyme patterns and showed that the two groups exhibited differences in the size of $\mathrm{X}$ and $\mathrm{Y}$ chromosomes. Further studies by the same author indicated that the two groups actually represent two cryptic 
species, naming them as $A$. sp.1 affine fraterculus and A. sp.2 affine fraterculus [28]. Also a probable third species in the $A$. fraterculus complex present in coastal locations of Brazil [92] and a fourth one from Ecuador [92] were described. Recently, Goday et al. [29] have analysed the heterochromatin organisation in mitotic chromosomes of eight Anastrepha species, including the four putative members of the fraterculus complex, using fluorescent staining and C-banding. The supposed distribution of one of them, "sp1", includes Argentina [29].

In Argentina, the initial report (in 1999 by Lifschitz et al.) of chromosomes of local populations of $A$. fraterculus [93] described a karyotype composed of five pairs of homomorphic and acrocentric autosomes, an acrocentric $\mathrm{X}$ chromosome and a small submetacentric $\mathrm{Y}$ chromosome whose length is approximately $2 / 3$ of the $\mathrm{X}$ length (please refer to Figure 3 ). The autosomes were reported as almost indistinguishable from each other except for the longer chromosome 2 (Figure 3). C banding revealed two terminal blocks of heterochromatin in the $\mathrm{X}$ chromosome. The $\mathrm{Y}$ chromosome shows a pericentric $\mathrm{C}$ band. A detailed C-banding ideogram and an $\mathrm{N}$-banding ideogram of this karyotype were published in 2003 [94]. This karyotype was the prevalent in all the samples studied in Argentina. However, occasional polymorphism of the sex chromosomes was present [94] (see also [95]). Four morphological variants of the $\mathrm{Y}$ chromosome and five variants of the $\mathrm{X}$ chromosome were reported to be present at low frequency in different samples of several localities in Argentina [93,96].

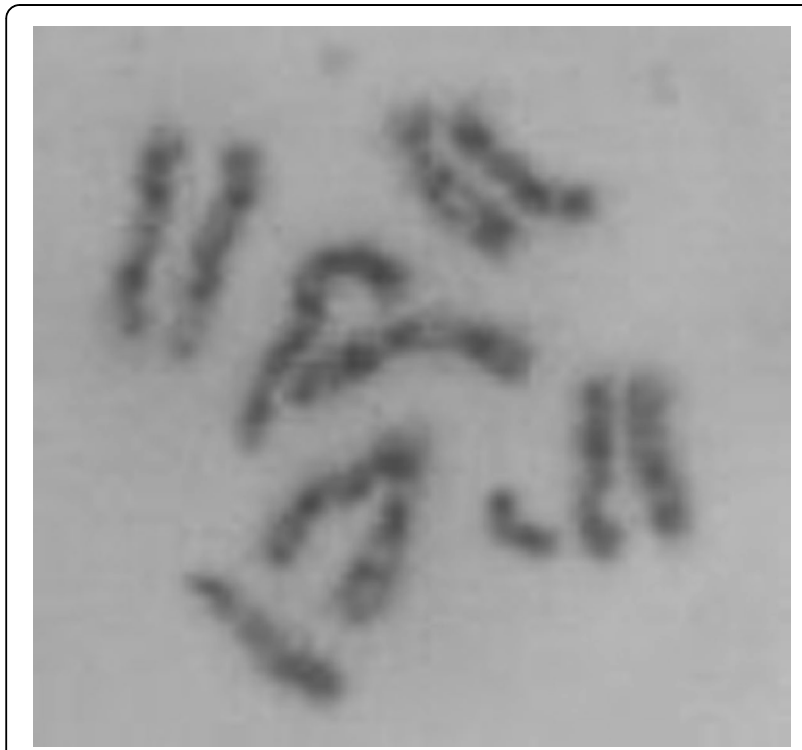

Figure 3 Mitotic chromosomes of $\boldsymbol{A}$. fraterculus. Somatic pairing of the five pairs of acrocentric autosomes, with the longer chromosome 2 in the center; the acrocentric $X$ chromosome and the small sub metacentric $Y$ chromosome are not paired
Laboratory strains carrying two different $\mathrm{X}$ and four different $Y$ chromosomes, as well as two configurations for one of the autosomes, were later isolated. The viability and the survival for several generations of these strains as well as of individuals with different hybrid configurations [94] proved that the different chromosomal configurations found in the $A$. fraterculus populations studied in Argentina do not represent any indication of reproductively separated species, but rather, mere examples of chromosome polymorphisms [95].

A study of mitotic metaphase in hybrids between $A$. fraterculus from Argentina and Peru was included by Cáceres et al. [18] in a multidisciplinary approach to investigate isolation between cryptic species of this complex. These two strains could be differentiated by the size and morphology of their mitotic sex chromosomes; the Argentinian strain had a large X-chromosome (XA) with two prominent $\mathrm{C}$-bands located at two tips, one band being larger than the other. The Argentinian Ychromosome (YA) was smaller than the XA and also shows two C-bands, one on the proximal tip and the other in the sub-median region. In the Peruvian strain, both $\mathrm{X}$ - and Y-chromosomes were large and similar in size (XP and YP respectively). In the hybrid strain, some of the expected sex chromosome cytotypes (XAXP, XPXP, XAYA, XPYA, XAXA) were observed, as well as larvae with 13 chromosomes, either XXX or XXY, both with XA chromosomes [18].

The existence of giant (polytene) chromosomes present in the salivary glands of $A$. fraterculus was already reported in 1958 by Mendes [88], but it was not until 2009 when Giardini et al. [97] provided the first pictures of the polytene chromosomes of $A$. fraterculus. They identified each chromosome on the basis of constant morphological structures (landmarks) and specific features (e.g., puffing pattern). The authors also performed an approximation to the linear map of polytene chromosomes following the customary labelling system. A simultaneous analysis of mitotic and polytene nuclei carried out to determine the sex of the larva showed that neither the number of polytene chromosomes nor their banding patterns differentiate males from females, indicating that sex chromosomes do not form polytene chromosomes in A. fraterculus [97].

Also the polytene chromosomes were observed in the study mentioned above on hybrids between $A$. fraterculus from Argentina and Peru [18]. The banding patterns of the polytene chromosomes of the two parental strains were very similar, especially at the chromosome ends. The strain from Argentina showed very little polymorphism, whereas the Peruvian strain showed partial asynapsis and many inversions. The hybrids between strains (generations F1 and F2) confirmed significant similarities between both banding patterns as well as 
ample asynapsis along the chromosome complement, notably in almost all chromosome ends. An extensive asynapsis similar to that observed in the F1 and F2 hybrids was present even in the 14th and 20th generations of the follow up hybrid strain indicating that this level of incompatibility between Argentinian and Peruvian strains is maintained across generations [18].

\section{Population genetics of Anastrepha fraterculus}

Studies on population genetics of insect pests provide valuable information to on-going control actions and also for programmes that are under development and evaluation, as is the case of the SIT for A. fraterculus in Argentina. The research about the distribution of genetic variability in wild populations, their colonisation patterns and phylo-geography are important to understand biological related problems for the control of insect pest species. In addition, we need the genetic characterisation of laboratory populations and mass rearing strains used for experimental research and for the SIT, not only for the genetic identification of lab strains, but also for their differentiation from wild populations. This information about the insect pests is helpful to give a complete landscape of genetics and ecology of the species to be used by control programmes to develop or improve the monitoring of released insects. The essential tools in all these studies are the protein and molecular markers, which are going to be reviewed here.

Initial studies conducted by Morgante et al. in 1980 on A. fraterculus population from Brazil [20] reported larger isozymes variation within this taxon than among other species of the genus. They postulated the existence of four morphologically indistinguishable groups within Brazilian A. fraterculus, with major differences between the northeastern and the southern populations. Allozyme frequency differences among Brazilian samples were not associated to the host plant $[35,98]$. Samples from northeastern Brazil were grouped by Steck [99] with others from coastal Venezuela, Central America, and Mexico; whereas southern Brazil samples were grouped with Andean Venezuela, and Peru [99]. The restriction fragment length polymorphism of a region of mitochondrial DNA amplified by PCR (mtDNA PCR+RFLP) was used to compare populations from Venezuela and Brazil, showing significant differences between lowland and Andean population. Both isozyme and mtDNA PCR + RFLP patterns confirmed a limited gene flow between southern and northern populations from Brazil [100]. Using sequences of the large subunit ribosomal DNA (16S rDNA) of the mtDNA McPheron et al. [101] also found that samples of $A$. fraterculus from Brazil clustered separately from samples from Venezuela. Other authors, like Smith-Caldas et al. [24] studied the mtDNA variation using Cytochrome Oxidase (COI) gene sequences.
In the nominal species $A$. fraterculus, they distinguished 2 groups: 1) Andean populations that are separated from lowland Venezuelan populations and 2) Southern Brazilian population that is clustered together with the only population from Argentina that was included in the analysis.

In Argentina, although some $A$. fraterculus RAPD markers were reported in 1996 by Sonvico et al. [16] and isozymes were used in 1999 by Alberti et al. [102] in a genetic structure study (see below), the first extensive population genetic study of $A$. fraterculus was reported in 2002 by Alberti et al. [3]. Eight isozyme loci applied to nine populations from Argentina and restriction patterns of a PCR amplified mtDNA fragment (16S rDNA), studied in 11 Argentinian and one southern Brazilian populations, allowed these authors to arrive to the conclusion that all of these populations belong to the same species. Later Alberti et al. [103] sequenced a 417 bp fragment of the mtDNA COI gene and found no correlation between haplotypes and the geographic distribution in Argentina, finding new evidence against the presence of more than one species in the surveyed territory.

At a finer scale, a population structure study from Argentina compared the variation within and between fruits in flies emerging from guava collected at Yuto, in the northwest of Argentina [102]. The frequency of homozygote individuals was high, suggesting the existence of groups with a variable degree of genetic diversity, an unexpected genetic structure [102]. Recently the internal structure of a population in Tucumán was analysed applying ISSR (inter simple sequence repeats markers, developed at the University of Buenos Aires by Paulin et al. [104]). The variation within and among samples derived from different hosts was evaluated in relation to the chemical composition of these hosts by Oroño et al. [105]. The adaptation to plant chemistry appears to produce population differentiation. Besides, the differentiation is stronger between populations exploiting sympatric synchronic hosts differing in chemical composition than between populations that exploit hosts fruiting in succession [105].

Hopefully microsatellite markers, recently developed for $A$. fraterculus by Lanzavecchia et al. [106], may reveal higher levels of polymorphism in populations of this species than any other molecular tool so far available. About 140 regions analysed and 14 microsatellite loci selected already revealed remarkably high genetic variability in the four populations (two wild and two lab strains) used to test the markers in Argentina. These markers may also be used to study the genetic changes suffered by a wild population of $A$. fraterculus during the process of introduction into artificial rearing. Scannapieco et al. [107] demonstrated loss of genetic variability across the first few generations during the domestication process, similarly as described for other Tephritidae species $[108,109]$. 
These new microsatellite markers are currently being applied in our laboratory to the analysis of the genetic diversity in wild $A$. fraterculus populations from Argentina and Brazil.

We showed here some genetic and molecular tools used to characterise $A$. fraterculus at species and intra species levels with emphasis on information recorded from specific geographic regions in Argentina. One important challenge for the future will be to perform wider studies and careful analysis of population genetics with application of standardised methodology and the development of common DNA markers available to all researchers in the Americas to facilitate comparisons across borders. This knowledge would ensure having a complete picture of $A$. fraterculus genetics, information needed for the development and implementation of the SIT in this species.

\section{Anastrepha fraterculus isolation barriers}

In relation to the successful implementation of a SIT programme to control $A$. fraterculus in South America, the problem requiring most urgent attention lies in the existence of cryptic species. Whitten and Mahon [110] clearly explain this situation: If we are dealing with a group of distinct species or even subspecies with limited interbreeding, each taxon must be treated separately for the SIT, since sterile males must be competitive with the field males in seeking female mates; the situation of the cryptic species could be even worse if the mating barriers are undetected because of the lack of relevant biological knowledge [110]. For this reason, the existence of at least seven cryptic species within the "Anastrepha fraterculus complex" [111] has become an incentive for the research on the existence of reproductive barriers and isolation mechanisms, as well as the degree of gene flow among them.

Pre-zygotic as well as post-zygotic isolation mechanisms among cryptic species of the A. fraterculus complex have been described. For instance, $A$. fraterculus sp. 1 and $A$. fraterculus sp. 2 from Brazil were crossed by Selivon et al. obtaining some reduction in the F1 egg hatch and sex ratio distortion [112]. In a larger experiment (including populations from Argentina, Brazil, Colombia and Peru), Vera et al. showed pre-mating isolation between flies from Peru and the other three populations, as well as between flies from Piracicaba (São Paulo, Brazil) and Argentina [27]. Moreover, flies from these two latter origins mate preferentially early in the morning, while Colombian flies mate late in the afternoon, and Peruvian flies mate preferentially around noon [27]. High levels of mating isolation were also found among Mexican, Peruvian and the Brazilian-1 morphotypes [113]. Here, the differences in morphology and genetics were correlated with the existence of limited gene flow, and post-zygotic mechanisms were also detected; however, their relative contribution to reproductive isolation was lower than pre-zygotic barriers [113].

The mechanisms behind the pre- and post-zygotic isolation barriers in the $A$. fraterculus complex are not well understood. In the previously mentioned study of hybrids between strains from Argentina and Peru [18], Cáceres et al. have found differences both in quality and quantity of certain parental pheromone compounds. Hybrid males' pheromone has been found to be a mix of the parental pheromones $[18,114]$. Interestingly, parental females did not discriminate between the males of their own strain and hybrid males [18], but hybrid females showed a marked preference for hybrid males [114]. In the chromosomes section, we have already mentioned extensive asynapsis in this hybrid between the Argentinian and Peruvian strains, suggesting significant genetic differentiation [18].

Petit Marty et al. $[66,67]$ confronted A. fraterculus flies from extreme regions (NOA and NEA) inside Argentina. The authors determined the frequency of homotypic and heterotypic crosses in a large experiment under field cage conditions. No evidence of sexual incompatibility was found, either pre-zygotic [67] or post-zygotic [66]. These studies confirmed the presence of a single $A$. fraterculus biological entity in Argentina. In an attempt to delimit the boundaries of this morphotype that inhabits Argentina and extends to southern Brazil, Rull et al. [113] carried out pre- and post-zygotic tests, including two populations from Rio Grande do Sul, Brazil (Vacaria and Pelotas) and one population from Argentina (Tucumán), and found no evidence of sexual isolation among these populations, making a valuable contribution to the definition of the area occupied by this morphotype.

\section{The sterile insect technique and Anastrepha fraterculus}

The idea of releasing insects of pest species to introduce sterility into wild populations, and thus control them, goes historically back to the 1930s and 1940s (see [115] for a review). The SIT is "a method of pest control using area-wide inundative release of sterile insects to reduce reproduction in a field population of the same species" [116]. Essentially, the SIT involves rearing a very large number of target species individuals, exposing them to ionising radiation (or chemosterilants) to induce sexual sterility and then releasing them into the target population where the sterile males mate with wild females preventing them from reproducing.

There are technical requirements as well as management and logistical prerequisites for a SIT programme to succeed [117]. The technical requirements are: availability of baseline data to develop an appropriate strategy, adequate competitiveness of the sterile males, mating 
compatibility between the strain used for release and the target population, assurance and persistence of the quality of the released strain and sound monitoring [117]. The management / logistical prerequisites are: commitment of all stakeholders, enough resources (funding, manpower and institutional capacity), flexible and independent management structure with dedicated full time staff, independent programme reviews, continuity in the implementation of critical programme components, data analysis plus feedback mechanisms, and public education and awareness [117]. For the existence of an A. fraterculus SIT programme in Argentina, we must say that presently most of the management prerequisites are still missing. In contrast, nearly all technical requirements have been fulfilled or are about to be.

The different aspects of the SIT have been thoroughly gathered in the book by Dyck, Hendrichs and Robinson [118]. There, the following technical components of the SIT are reviewed : 1) population and behavioural ecology, 2) mass rearing of the insect, 3) sterilisation with radiation, 4) quality of the sterile insect, 5) processes of supply, emergence and release, 6) monitoring of sterile and wild insects, and 7) a procedure for declaring the pest free status. In connection with the development of the SIT for A. fraterculus in Argentina most of these issues have been treated in the preceding sections; so we quickly retrieve them here in the aforementioned context.

Several genetic aspects of $A$. fraterculus populations from Argentina have been investigated $[3,102,103,105,106]$, dispersal distances have been estimated [33-36] and the components of a successful sexual competitiveness dissected $[5,63,75]$. Estimating the fluctuations in the target population, the number of sterile males to be released, the density and the mortality rates are recommended by Ito and Yamamura [119]. These estimations for A. fraterculus are still missing.

Artificial-rearing of $A$. fraterculus has been investigated $[12,13,45]$, the research on diet and nutritional requirements has also advanced [48]. But the up-scaling process to reach the production levels needed for the SIT has not been focus of research so far. Some of the issues that should be addressed are: facility design, environmental concerns, strain management, automation, sex separation, marking and storage [120].

Sterilisation with radiation of the $A$. fraterculus present in Argentina has been obtained [82,84,85]; the absorbed dose ensuring that treated insects are sufficiently sterile and yet able to compete for mates with wild insects is $70 \mathrm{~Gy}$, applied $48 \mathrm{~h}$ before adult emerge. It is known that the oxygen level during irradiation influences both the absorbed dose required for sterilisation and the viability of irradiated insects [80]. However, irradiation in anoxia has not been investigated in this system up to now.
Quality, in terms of the ability of the insect to survive, interact with its environment, locate, mate and fertilise females of the target population has been tested for artificially reared $A$. fraterculus in field-cage tests under seminatural conditions, where sterile males have to compete with wild males for wild females $[36,46,58,60,62]$. However, a compartmentalised system of bioassays for quality parameters assessment in the factory (cf. [121]) has not been completed yet.

Supply, emergence and release processes of the SIT for A. fraterculus were not investigated so far. Dowel, Worley and Gomes [122] recommend rearing insects in modules because this system offers flexibility and increases safety, compared to housing all the rearing process in a single building. Alternatively insects can be produced from purchased eggs or, adult insects may be obtained from specialised satellite facilities [122]. The release of sterile insects may be via static-release receptacles, ground-release systems or from the air, but aircraft guided by GPS and computer controlled release of chilled sterile insects has proved to be most efficient [122].

A number of technical tools to monitor sterile $A$. fraterculus after released in the field, for instance sexual competitiveness [12], survival $[36,46]$, mobility, dispersal [33-36], etc. are already available. However, research is still needed on the evaluation of sterility induced in the wild population. This is the most important parameter to be monitored according to Vreysen [123], because it provides the best evidence that the release of sterile insects causes changes in the density of the target insect.

Declaring an area to be pest free is not easy. In the case of $A$. fraterculus there is an obvious need of research on the subject. For instance Barclay, Hargrove, Clift and Meats [124] proposed a procedure involving models to deal with null trapping results and to help verify that pests are no longer present after control actions are stopped. These models depend on knowledge of the efficiency and the area of attractiveness of the traps. Above all, the most urgent need in the development of the SIT for A. fraterculus is finding a specific lure and designing a specific trap.

\section{Future research on Anastrepha fraterculus}

The isolation and characterisation of specific microsatellite markers for A. fraterculus [106] opens a wide door to perform genetic analyses in wild populations of this pest. Valuable information on their genetic structure, dispersion patterns, and distribution of genetic variants is foreseen. In addition, these molecular markers will help in the species elucidation within the A. fraterculus complex (J Silva, $S$ Lanzavecchia and others, work in progress).

These markers are also useful for exploring changes in the genetic variability suffered by a wild population of A. fraterculus during adaptation to artificial rearing [107]. A complete picture of the dynamics of genetic 
variability changes during laboratory adaptation should provide better quality control protocols for factory strains of this pest.

The extended asynapsis shown in the polytene chromosomes of F1 and F2 hybrids between two cryptic species [18] indicate an interesting venue of future research in the clarification of different entities in the A. fraterculus complex. This will be possible after a detailed map (presently under progress by Giardini, Zacharopoulou and others) becomes available.

Several genes involved in sex determination have been characterised in A. fraterculus and other Anastrepha species [125-128]. The elucidation of the mechanism driving early embryos to either the female or the male developmental pathway (see [129]) should be an obvious target of future research.

Key pheromone components of courtship and their roles as attractants to the two sexes have been overlooked in A. fraterculus. This information has several implications, such as understanding the basis of increased sexual performance after aroma exposure or protein supply, the identification of compounds that may act as sexual isolation barriers and the development of artificial attractants for mass-trapping programmes.

Genetic drift and artificial selection associated with rearing conditions could have detrimental effects on the ability of laboratory males to compete for mating in nature. This ability should be assessed in mass-rearing facilities to determine the quality of released males. A better understanding of the courtship behaviour in A. fraterculus could also help to understand the basis of the reproductive isolation between different morphotypes (cf. [70]).

The exact number and distribution of each entity in the A. fraterculus complex is not known. This knowledge would be extremely important to understand the real structure of the complex and to design effective control methods based on the SIT. About the barriers for reproduction between morphotypes, future research might address subjects as reproductive barriers at the micro-scale (cf. [105]), the role of sex pheromones and cuticle hydrocarbons in the recognition of sexes, or the role that Wolbachia might be playing in the build-up of reproductive barriers between members of the $A$. fraterculus complex.

\section{Competing interests}

The authors declare that they have no competing interests.

\section{Aknowledgements}

The careful critical reading by Don McInnis, Kostas Bourtzis and an anonymous reviewer are much appreciated. Grants from the following agencies are acknowledged: Agencia Nacional Promoción Ciencia y Técnica: through PIC 1320-2010 (to DFS). International Atomic Energy Agency: though RC 15745 (to SBL). Universidad Buenos Aires, through UBACYT 20112014 No 20020100100557 (to JCV).
This article has been published as part of BMC Genetics Volume 15 Supplement 2, 2014: Development and evaluation of improved strains of insect pests for SIT. The full contents of the supplement are available online at http://www.biomedcentral.com/bmcgenet/supplements/15/S2. Publication of this supplement was funded by the International Atomic Energy Agency. The peer review process for articles published in this supplement was overseen by the Supplement Editors in accordance with BioMed Central's peer review guidelines for supplements. The Supplement Editors declare that they have no competing interests.

\section{Authors' details}

${ }^{1}$ Instituto Genética EA Favret, Instituto Nacional Tecnología Agropecuaria, 1686 Hurlingham, Provincia Buenos Aires, Argentina. ${ }^{2}$ Departamento Ecología, Genética y Evolución, Facultad Ciencias Exactas y Naturales, Universidad Buenos Aires; 1428 Ciudad Autónoma Buenos Aires, Argentina. ${ }^{3}$ Instituto de Ecología, Genética y Evolución de Buenos Aires, Consejo Nacional de Investigaciones Científicas y Técnicas, Buenos Aires, Argentina.

Published: 1 December 2014

\section{References}

1. Vergani AR: Distribución geográfica de las moscas de los frutos en la Argentina. IDIA 1956, 99:1-5.

2. Cabrera A, Willink A: Biogeografía de América Latina. Secretaría General de la organización de los Estados Americanos. Serie de Biología. In Monogr Científicas la OEA OEA. Buenos Aires, Argentina 1980.

3. Alberti AC, Rodriguero MS, Gómez-Cendra PV, Saidman BO, Vilardi JC: Evidence indicating that Argentine populations of Anastrepha fraterculus (Diptera: Tephritidae) belong to a single biological species. Ann Entomol Soc Am 2002, 95:505-512.

4. Segura DF, Vera MT, Cagnotti CL, Vaccaro N, De Coll O, Ovruski SM, Cladera JL: Relative Abundance of Ceratitis capitata and Anastrepha fraterculus (Diptera: Tephritidae) in Diverse Host Species and Localities of Argentina. Ann Entomol Soc Am 2006, 99:70-83.

5. Gómez-Cendra PV, Segura DF, Alberti AC, Vilardi JC: Morphometric trait differentiation between a wild and a mass-reared population of Anastrepha fraterculus (Diptera: Tephritidae). Int J Trop Insect Sci 2014.

6. Salles $L A B$ : Estratificacao vertical da incidencia de Anastrepha fraterculus (Wied.) em fruteiras no sul do Brasil. An da Soc Entomológica do Bras 1995, 24:423-428.

7. Steck GJ: Taxonomic status of Anastrepha fraterculus. South Am Fruit Fly, Anastrepha Frat (Weid); Adv Artif rearing, taxonimic status Biol Stud IAEATECDOC-1064 Vienna, Austria: IAEA; 1999.

8. Norrbom AL: Host plant database for Anastrepha and Toxotrypana (Diptera: Tephritidae: Toxotrypani) 2004, CD - not a journal.

9. Ovruski SM, Schliserman P, Aluja M: Native and introduced host plants of Anastrepha fraterculus and Ceratitis capitata (Diptera: Tephritidae) in northwestern Argentina. J Econ Entomol 2003, 96:1108-1118.

10. IAEA: The South American Fruit Fly, Anastrepha Fraterculus (Wied.); Advances in Artificial Rearing, Taxonomic Status and Biological Studies IAEA-TECDOC1064 Vienna, Austria: IAEA; 1999.

11. Ortíz G: Potential use of the sterile insect technique against the South American fruit fly. South Am Fruit Fly, Anastrepha Frat (Weid); Adv Artif rearing, taxonimic status Biol Stud IAEA-TECDOC-1064 Vienna, Austria: IAEA; 1999, 121-130.

12. Vera MT, Abraham S, Oviedo A, Willink E: Demographic and quality control parameters of Anastrepha fraterculus (Diptera: Tephritidae) maintained under artificial rearing. Florida Entomol 2007, 90:53-57.

13. Salles LAB: Metodología de criaçao de Anastrepha fraterculus (Wied, 1830) (Diptera: Tephritidae) em dieta artificial em laboratorio. An da Soc Entomológica do Bras 1992, 21:479-486.

14. Salles $L A B$ : Influencia do fotoperiodo no desenvolvimento de Anastrepha fraterculus (Wied., 1830) (Diptera: Tephritidae). An da Soc Entomológica do Bras 1993, 22:47-55.

15. Salles $L A B$ : Emergencia dos adultos de Anastrepha fraterculus durante o outono e inverno em Pelotas, RS. An da Soc Entomológica do Bras 1993, 22:63-69.

16. Sonvico A, Manso FC, Quesada-Allue LA: Discrimination between the immature stages of Ceratitis capitata and Anastrepha fraterculus (Diptera: Tephritidae) populations by random amplified polymorphic DNA polymerase chain reaction. J Econ Entomol 1996, 89:1208-1212. 
17. González Bachini J: Irradiación de Anastrepha fraterculus (Wied.). Rev Peru Entomol 1971, 14:77-79.

18. Cáceres C, Segura DF, Vera MT, Wornoayporn V, Cladera JL, Teal PEA, Sapountzis P, Bourtzis K, Zacharopoulou A, Robinson AS: Incipient speciation revealed in Anastrepha fraterculus (Diptera; Tephritidae) by studies on mating compatibility, sex pheromones, hybridization, and cytology. Biol J Linn Soc 2009, 97:152-165.

19. Stone A: The fruitflies of the genus Anastrepha. USDA Misc Publ 1942, 439:112.

20. Morgante JS, Malavasi A, Bush GL: Biochemical systematics and evolutionary relationships of neotropical Anastrepha. Ann Entomol Soc Am 1980, 73:622-630

21. Malavasi A, Morgante JS: Population genetics of Anastrepha fraterculus (Diptera, Tephritidae) in different hosts: Genetic differentiation and heterozygosity. Genetica 1983, 60:207-211.

22. Selivon D, Morgante JS, Perondini ALP: Egg size, yolk mass extrusion and hatching behavior in two cryptic species of Anastrepha fraterculus (Wiedemann) (Diptera, Tephritidae). Brazilian J Genet 1997, 20:587-594.

23. Dos Santos P, Uramoto K, Matioli SR: Experimental hybridization among Anastrepha species (Diptera: Tephritidae): production and morphological characterization of F1 hybrids. Ann Entomol Soc Am 2001, 94:717-725.

24. Smith-Caldas MR, McPheron BA, Silva JG, Zucchi RA: Phylogenetic relationships among species of the fraterculus group (Anastrepha: Diptera: Tephritidae) inferred from DNA sequences of mitochondrial cytochrome oxidase I. Neotrop Entomol 2001, 30:565-573.

25. Rocha LS, Selivon D: Studies on highly repetitive DNA in cryptic species of the Anastrepha fraterculus complex (Diptera: Tephritidae). In Proc 6th Int Symp fruit flies Econ importance, Stellenbosch, South Africa, 6-10 May 2002. Irene, South Africa: Isteg Scientific Publications;Barnes BN 2004:415-418.

26. Hernández-Ortiz V, Gómez-Anaya JA, Sánchez A, McPheron BA, Aluja M: Morphometric analysis of Mexican and South American populations of the Anastrepha fraterculus complex (Diptera: Tephritidae) and recognition of a distinct Mexican morphotype. Bull Entomol Res 2004, 94:487-499.

27. Vera MT, Cáceres C, Wornoayporn V, Islam A, Robinson AS, De La Vega MH, Hendrichs J, Cayol J-P: Mating incompatibility among populations of the South American fruit fly Anastrepha fraterculus (Diptera: Tephritidae). Ann Entomol Soc Am 2006, 99:387-397.

28. Selivon D, Perondini ALP, Morgante JS: A genetic - morphological characterization of two cryptic ppecies of the Anastrepha fraterculus complex (Diptera: Tephritidae). Ann Entomol Soc Am 2005, 98:367-381.

29. Goday C, Selivon D, Perondini ALP, Greciano PG, Ruiz MF: Cytological characterization of sex chromosomes and ribosomal DNA location in Anastrepha species (Diptera, Tephritidae). Cytogenet Genome Res 2006, 114:70-76.

30. Silva JG, Barr NB: Recent advances in molecular systematics of Anastrepha Schiner. In Proc 7th Int Symp Fruit Flies Econ Importance 10-15 Sept 2006, Salvador Brazil. Volume September. Biofábrica Moscamed Brasil Sugayama RL, Zucchi RA, Ovruski SM, Sivinski J 2008:13-28.

31. Lance DR, Mclnnis DO: Biological basis of the sterile insect technique. In Sterile Insect Tech Princ Pract Area-Wide Integr Pest Manag. Dordrecht, The Netherlands: Springer;Dyck VA, Hendrichs J, Robinson AS 2005:

32. Cáceres C, Mclnnis DO, Shelly TE, Jang EB, Robinson AS, Hendrichs J: Quality management systems for fruit fly (Diptera: Tephritidae) sterile insect technique. Florida Entomol 2007, 90:1-9.

33. Fletcher BS: Life history strategies of tephritid fruit flies. In Fruit Flies Their Biol Nat Enemies Control. Volume Volume 3B. Amsterdam: Elsevier;Robinson AS, Hooper G 1989.

34. Malavasi A, Morgante JS: Adult and larval population fluctuation of Anastrepha fraterculus and its relationship to host availability. Environ Entomol 1981, 10:275-278.

35. Malavasi A, Morgante JS, Prokopy RJ: Distribution and activities of Anastrepha fraterculus (Diptera: Tephritidae) flies on host and nonhost trees. Ann Entomol Soc Am 1983, 76:286-292.

36. Utgés ME: Supervivencia y dispersión en moscas de los frutos del género Anastrepha (Diptera: Tephritidae): efecto de la alimentación post-teneral Universidad de Buenos Aires; 2012.

37. Barros MD, Novaes M, Malavasi A: Estudos do comportamento de oviposicáo de Anastrepha fraterculus (Wiedemann, 1830) (Díptera, Tephritidae) em condicoes naturais e de laboratorio. An da Soc Entomológica do Bras 1983, 12:243-247.
38. Prokopy RJ, Malavasi A, Morgante JS: Oviposition deterring pheromone in Anastrepha fraterculus flies. J Chem Ecol 1982, 8:763-771.

39. González Bachini J: Crianza masal de Anastrepha fraterculus (Wied). Rev Peru Entomol 1971, 14:71-76.

40. Cardoso V V, Ferreira MP, Montagner JM, Fernández CG, Moreira JC, Oliveira AK: The effects of constant and alternating temperatures on the reproductive potential, life span, and life expectancy of Anastrepha fraterculus (Wiedemann) (Diptera: Tephritidae). Brazilian J Biol 2002, 62:775-786.

41. Alama D: Ensayos para determinar niveles de oviposicion de Anastrepha fraterculus (Wied.) sobre fruta y dispositivos artificiales. In South Am Fruit Fly, Anastrepha Frat (Weid); Adv Artif rearing, taxonimic status Biol Stud IAEATECDOC-1064. Vienna, Austria;IAEA 1999:

42. Salles LAB: Biology of Anastrepha fraterculus. South Am Fruit Fly, Anastrepha Frat (Weid); Adv Artif rearing, taxonimic status Biol Stud IAEATECDOC-1064 Vienna, Austria: IAEA; 1999.

43. Manso FC: Breeding technique of Anastrepha fraterculus (Wied.) for genetic studies. South Am Fruit Fly, Anastrepha Frat (Weid); Adv Artif rearing, taxonimic status Biol Stud IAEA-TECDOC-1064 Vienna, Austria: IAEA; 1999.

44. Nuñez Bueno L, Guzman Dueñas R: Avances sobre la cria artificial de Anastrepha fraterculus (Wied.) (Diptera: Tephritidae) en Colombia. In South Am Fruit Fly, Anastrepha Frat (Weid); Adv Artif rearing, taxonimic status Biol Stud IAEA-TECDOC-1064. Vienna, Austria: IAEA;IAEA 1999.

45. Jaldo HE, Gramajo C, Willink E: Mass rearing of Anastrepha fraterculus (Diptera: Tephritidae): a preliminary strategy. Florida Entomol 2001, 84:716-718.

46. Gómez-Cendra PV, Segura DF, Allinghi A, Cladera JL, Vilardi JC: Comparison of longevity between a laboratory strain and a natural population of Anastrepha Fraterculus (Diptera: Tephritidae) under field cage conditions. Florida Entomol 2007, 90:147-153.

47. Tsitsipis JA: Nutrition. In Fruit Flies: Their Biology, Natural Enemies and Control, Vol 3A - (World Crop Pests; 3A). Netherlands: Elsevier Science Publishers; Robinson AS, Hooper G 1989:103-119.

48. Oviedo A, Nestel D, Papadopoulos NT, Ruiz MJ, Prieto SC, Willink E, Vera MT: Management of protein intake in the fruit fly Anastrepha fraterculus. J Insect Physiol 2011, 57:1622-1630.

49. Shelly TE, Whittier TS, Kaneshiro K: Sterile Insect Release and the Natural Mating System of the Mediterranean Fruit Fly, Ceratitis capitata (Diptera: Tephritidae). Ann Entomol Soc Am 1994, 87:470-481.

50. Lance DR, Mclnnis DO, Rendón P, Jackson CG: Courtship among sterile and wild Ceratitis capitata (Diptera: Tephritidae) in field cages in Hawaii and Guatemala. Ann Entomol Soc Am 2000, 93:1179-1185.

51. Benedict MQ, Robinson AS: The first releases of transgenic mosquitoes: an argument for the sterile insect technique. Trends Parasitol 2003, 19:349-355.

52. Lima IS, House PE, Salles LAB: Reproductive behaviour of the south American fruit fly Anastrepha fraterculus (Diptera: Tephritidae): laboratory and field studies. Physiol Entomol 1994, 19:271-277.

53. Aluja M, Norrbom AL: Fruit Flies (Tephritidae): Phylogeny and Evolution of Behavior. Boca Raton, USA: CRC Press; 12000.

54. Enkerlin W: Guidance for Packing, Shipping, Holding and Release of Sterile Flies in Area-Wide Fruit Fly Control Programmes. Food \& Agriculture Org; 2007.

55. Teal PEA, Gomez-Simuta Y: Juvenile hormone: action in regulation of sexual maturity in Caribbean fruit flies and potential use in improving efficacy of sterile insect control technique for tephritid fruit flies. Int Organ Biol Integr Control Bull 2002, 25:1-15.

56. Nation JL: The structure and development of two sex specific glands in male Caribbean fruit flies. Ann Entomol Soc Am 1974, 67:731-734.

57. Salles LAB: Behaviour of Anastrepha fraterculus. South Am Fruit Fly, Anastrepha Frat (Weid); Adv Artif rearing, taxonimic status Biol Stud IAEATECDOC-1064 IAEA. Vienna, Austria; 1999.

58. Segura DF, Utgés ME, Liendo MC, Rodríguez MF, Devescovi F, Vera MT, Teal PEA, Cladera JL: Methoprene treatment reduces the pre-copulatory period in Anastrepha fraterculus (Diptera: Tephritidae) sterile males. J Appl Entomol 2013, 137:19-29, Special Issue: Improving Sterile Male Performance in Fruit Fly SIT Programmes.

59. Peralta PA, Milla FH, Cladera JL: Aportes a la Técnica de Insecto Estéril: Una cepa de Anastrepha fraterculus (Diptera: Tephritidae) con maduración sexual temprana. Rev Investig Agropecu INTA 2014, 40. 
60. Liendo MC, Devescovi F, Bachmann GE, Utgés ME, Abraham S, Vera MT, Lanzavecchia SB, Bouvet JP, Gómez-Cendra PV, Hendrichs J, Teal PEA, Cladera JL, Segura DF: Precocious sexual signalling and mating in Anastrepha fraterculus (Diptera: Tephritidae) sterile males achieved through juvenile hormone treatment and protein supplements. Bull Entomol Res 2013, 103:1-13.

61. Segura DF, Cáceres C, Vera MT, Wornoayporn V, Islam A, Teal PEA, Cladera $J L$, Hendrichs J, Robinson AS: Enhancing mating performance after juvenile hormone treatment in Anastrepha fraterculus : a differential response in males and females acts as a physiological sexing system. Entomol Exp Appl 2009, 131:75-84

62. Abraham S, Liendo MC, Devescovi F, Peralta PA, Yusef V, Ruiz J, Cladera JL, Vera MT, Segura DF: Remating behavior in Anastrepha fraterculus (Diptera: Tephritidae) females is affected by male juvenile hormone analog treatment but not by male sterilization. Bull Entomol Res 2013, 103:310-317.

63. Segura DF, Petit-Marty N, Sciurano R, Vera MT, Calcagno G, Allinghi A, Gómez-Cendra PV, Cladera JL, Vilardi JC: Lekking behavior of Anastrepha fraterculus (Diptera: Tephritidae). Florida Entomol 2007, 90:154-162.

64. Morgante JS, Malavasi A, Prokopy RJ: Mating behavior of wild Anastrepha fraterculus (Diptera: Tephritidae) on a caged host tree. Florida Entomol 1983, 66:234-241.

65. Aluja M, Piñero J, Jácome I, Díaz-Fleischer F, Sivinski J: Behavior of flies in the genus Anastrepha (Trypetinae: Toxotrypanini). In Fruit Flies Phylogeny Evol Behav. Boca Raton, USA: CRC Press;Aluja M, Norrbom AL 2000:375-408.

66. Petit-Marty N, Vera MT, Calcagno G, Cladera JL, Vilardi JC: Lack of postmating isolation between two populations of Anastrepha fraterculus from different ecological regions in Argentina. In Proc 6th Int Symp fruit flies Econ importance, Stellenbosch, South Africa, 6-10 May 2002. Irene, South Africa: Isteg Scientific Publications;Barnes BN 2004:

67. Petit-Marty N, Vera MT, Calcagno G, Cladera JL, Segura DF, Allinghi A, Rodriguero MS, Gómez-Cendra PV, Viscarret MM, Vilardi JC: Sexual behavior and mating compatibility among four populations of Anastrepha fraterculus (Diptera: Tephritidae) from Argentina. Ann Entomol Soc Am 2004, 97:1320-1327.

68. Gómez-Cendra PV, Calcagno G, Belluscio L, Vilardi JC: Male courtship behavior of the South American fruit fly, Anastrepha fraterculus, from an Argentinean laboratory strain. J Insect Sci 2011, 11:175.

69. Mankin RW, Malavasi A, Aquino C: Acoustical comparisons of calling songs from Anastrepha species in Brazil. In Fruit Fly Pests A World Assess Their Biol Manag.. 1 edition. Florida, USA: St. Lucie Press;McPheron BA, Steck GJ 1996:37-42.

70. Joachim-Bravo IS, Laumann R, Dias VS, Passos Roriz AK, Petitinga CSCD, Jordão Paranhos BA, Malavasi A: Analysis of Ecological Speciation among Anastrepha Fraterculus Populations from Brazil through Behavioral and Demographic Parameters. 2013.

71. Lima IS, House PE, Stevens IRD: Volatile components from the salivary glands of calling males of the South American fruit fly, Anastrepha fraterculus: partial identification and behavioral activity. In Fruit Fly Pests A World Assess Their Biol Manag.. 1 edition. Florida, USA: St. Lucie Press; McPheron BA, Steck GJ 1996:107-113.

72. Břízová $R$, Mendonça $A L$, Vanícková $L$, Mendonça $A L$, Da Silva $C E$, Tomčala A, Jordão Paranhos BA, Dias VS, Joachim-Bravo IS, Hoskovec M, Kalinová B, Do Nascimento RR: Pheromone Analyses of the Anastrepha fraterculus ( Diptera: Tephritidae ) Cryptic Species Complex. Florida Entomol 2013, 96:1107-1115.

73. Pereira R, Yuval B, Liedo P, Teal PEA, Shelly TE, McInnis DO, Hendrichs J: Improving sterile male performance in support of programmes integrating the sterile insect technique against fruit flies. J Appl Entomol 2013, 137:178-190

74. Vera MT, Ruiz MJ, Oviedo A, Abraham S, Mendoza M, Segura DF, Kouloussis NA, Willink E: Fruit compounds affect male sexual success in the South American fruit fly, Anastrepha fraterculus (Diptera: Tephritidae). J Appl Entomol 2013, 137:2-10.

75. Sciurano R, Segura DF, Rodriguero MS, Gómez-Cendra PV, Allinghi A, Cladera JL, Vilardi JC: Sexual Selection on Multivariate Phenotypes in Anastrepha fraterculus (Diptera: Tephritidae) From Argentina. Florida Entomol 2007, 90:163-170.

76. Abraham S, Goane L, Rull J, Cladera JL, Willink E, Vera MT: Multiple mating in Anastrepha fraterculus females and its relationship with fecundity and fertility. Entomol Exp Appl 2011, 141:15-24.
77. Abraham S, Goane L, Cladera JL, Vera MT: Effects of male nutrition on sperm storage and remating behavior in wild and laboratory Anastrepha fraterculus (Diptera: Tephritidae) females. J Insect Physiol 2011, 57:1501-1509.

78. Abraham S, Goane L, Cladera JL, Vera MT: Factors affecting Anastrepha fraterculus female receptivity modulation by accessory gland products. J Insect Physiol 2012, 58:1-6.

79. Robinson AS: Genetic basis of the sterile insect technique. In Sterile Insect Tech Princ Pract Area-Wide Integr Pest Manag. Dordrecht, The Netherlands: Springer;Dyck VA, Hendrichs J, Robinson AS 2005:

80. Bakri A, Metha K, Lance DR: Sterilizing insects with ionizing radiation. In Sterile Insect Tech Princ Pract Area-Wide Integr Pest Manag. Dordrecht, The Netherlands: Springer;Dyck VA, Hendrichs J, Robinson AS 2005:.

81. Bakri A, Heather N, Hendrichs J, Ferris I: Fifty years of radiation biology in entomology: lessons learned from IDIDAS. Ann Entomol Soc Am 2005, 98:1-12.

82. Allinghi A, Gramajo C, Willink E, Vilardi JC: Induction of sterility in Anastrepha fraterculus (Diptera: Tephritidae) by gamma radiation. Florida Entomol 2007, 90:96-102.

83. FAO/IAEA/USDA: Manual for Product Quality Control and Shipping Procedures for Sterile Mass-Reared Tephritid Fruit Flies, Version 5.0. Vienna, Austria; 2003.

84. Allinghi A, Calcagno G, Petit-Marty N, Gómez-Cendra PV, Segura DF, Vera MT, Cladera JL, Gramajo C, Willink E, Vilardi JC: Compatibility and competitiveness of a laboratory strain of Anastrepha fraterculus (Diptera: Tephritidae) after irradiation treatment. Florida Entomol 2007, 90:27-32.

85. Bartolucci AF, Vera MT, Yusef V, Oviedo A: Morphological characterization of the reproductive system of irradiated Anastrepha fraterculus. In Proc 7th Int Symp Fruit Flies Econ Importance 10-15 Sept 2006, Salvador Brazil. Volume September 2006. Biofábrica Moscamed Brasil;Sugayama RL, Zucchi RA, Ovruski SM, Sivinski J 2008:45-52.

86. Mastrangelo T, Parker AG, Jessup A, Pereira R, Orozco-Dávila D, Islam A, Dammalage T, Walder JMM: A new generation of $\times$ ray irradiators for insect sterilization. J Econ Entomol 2010, 103:85-94.

87. Bachmann GE: Establecimiento de dosis de radiación de larvas de Anastrepha fraterculus (Diptera: Tephritidae) para la cría y liberación del parasitoide Diachasmimorpha longicaudata (Hymenoptera: Braconidae). Universidad de Buenos Aires; 2011.

88. Mendes LOT: Observacoes citologicas em moscas das frutas. Bragantia 1958, 17:29-39.

89. Bush GL: The cytotaxonomy of the larvae of some Mexican fruit flies in the genus Anastrepha. Psyche (Stuttg) 1962, 68:87-101.

90. Solferini VN, Morgante JS: Karyotype study of eight species of Anastrepha (Diptera: Tephritidae). Caryologia 1987, 40:229-241.

91. Selivon D: Estudo sobre a diferenciação populacional em Anastrepha fraterculus (Wiedemann) (Diptera: Tephritidae). Universidade de Sao Paulo; 1996.

92. Selivon D, Vretos C, Fontes L, Perondini ALP: New variant forms in the Anastrepha fraterculus complex (Diptera: Tephritidae). In Proc 6th Int Symp fruit flies Econ importance, Stellenbosch, South Africa, 6-10 May 2002. Stellenbosch, South Africa: Isteg Scientific Publications;Barnes BN 2004:253-258.

93. Lifschitz E, Manso FC, Basso A: Karyotype study of the South American Fruit-Fly, Anastrepha fraterculus (Wied.) in Argentina. South Am Fruit Fly, Anastrepha Frat (Weid); Adv Artif rearing, taxonimic status Biol Stud IAEATECDOC-1064 Vienna, Austria: IAEA; 1999.

94. Basso A, Sonvico A, Quesada-Allue LA, Manso FC: Karyotypic and molecular identification of laboratory stocks of the South American fruit fly Anastrepha fraterculus (Wied) (Diptera: Tephritidae). J Econ Entomol 2003, 96:1237-1244.

95. Basso A, Manso FC: Are Anastrepha fraterculus chromosomal polymorphisms an isolation barrier? Cytobios 1998, 93:103-111.

96. Manso FC, Basso A: Notes on the present situation of Anastrepha fraterculus in Argentina. In South Am Fruit Fly, Anastrepha Frat (Weid); Adv Artif rearing, taxonimic status Biol Stud IAEA-TECDOC-1064. Vienna, Austria;IAEA 1999.

97. Giardini MC, Milla FH, Manso FC: Structural map of the polytene chromosomes from the salivary glands of South American fruit fly Anastrepha fraterculus Wied. (Diptera, Tephritidae). Caryologia 2009, 62:204-212.

98. Morgante JS, Malavasi A: Genetic variability in populations of the SouthAmerican fruit fly Anastrepha fraterculus (Tephritidae). Rev Bras Genet 1985, 8:241-247. 
99. Steck GJ: Biochemical systematics and population genetic structure of Anastrepha fraterculus and related species (Diptera: Tephritidae ). Ann Entomol Soc Am 1991, 84:10-28.

100. Steck GJ, Sheppard WS: Mitochondrial DNA variation in Anastrepha fraterculus. In Fruit Flies Biol Manag. New York: Springer Verlag;Aluja M, Liedo P 1993

101. McPheron BA, Han H-Y, Silva JG, Norrbom AL: Phylogeny of the genera Anastrepha and Toxotrypana (Trypetinae: Toxotrypanini) based upon 16S rRNA mitochondrial DNA sequences. In Fruit Flies Phylogeny Evol Behav. Boca Raton, USA: CRC Press;Aluja M, Norrbom AL 2000:343-361.

102. Alberti AC, Calcagno G, Saidman BO, Vilardi JC: Analysis of the genetic structure of a natural population of Anastrepha fraterculus (Diptera: Tephritidae). Ann Entomol Soc Am 1999, 92:731-736.

103. Alberti AC, Confalonieri VA, Zandomeni RO, Vilardi JC: Phylogeographic studies on natural populations of the South American fruit fly, Anastrepha fraterculus (Diptera: Tephritidae). Genetica 2008, 132:1-8.

104. Paulin LE, Alberti AC, Oroño LE, Ovruski SM, Aluja M, Vilardi JC: Diferenciación genética entre poblaciones de Anastrepha fraterculus (Diptera, Tephritidae) asociadas a distintos hospederos. Proc XXXVII Congr Argentino Genética BAG XIX Tandil, Argentina; 2008.

105. Oroño LE, Paulin LE, Alberti AC, Hilal M, Ovruski SM, Vilardi JC, Rull J, Aluja M: Effect of host plant chemistry on genetic differentiation and reduction of gene flow among Anastrepha fraterculus (Diptera: Tephritidae) populations exploiting sympatric, synchronic hosts. Environ Entomol 2013, 42:790-798.

106. Lanzavecchia SB, Juri M, Bonomi A, Gomulski L, Scannapieco AC, Segura DF, Malacrida A, Cladera JL, Gasperi G: Isolation and characterization of microsatellite markers from the South American fruit fly, Anastrepha fraterculus (Diptera: Tephritidae). BMC Genet 2014, 15(Suppl 2):S13.

107. Parreño MA, Scannapieco AC, Juri M, Remis MI, Vera MT, Segura DF, Cladera JL, Lanzavecchia SB: Dynamics of genetic variability in Anastrepha fraterculus (Diptera: Tephritidae) during adaptation to laboratory conditions of rearing. BMC Genet 2014, 15(Suppl 2):S14.

108. Gilchrist AS, Cameron EC, Sved JA, Meats AW: Genetic Consequences of Domestication and Mass Rearing of Pest Fruit Fly Bactrocera tryoni (Diptera: Tephritidae). J Econ Entomol 2012, 105:1051-1056.

109. Zygouridis NE, Augustinos AA, Zalom FG, Mathiopoulos KD: Analysis of olive fly invasion in California based on microsatellite markers. Heredity (Edinb) 2009, 102:402-12.

110. Whitten M, Mahon R: Misconceptions and constraints. In Sterile Insect Tech Princ Pract Area-Wide Integr Pest Manag. Dordrecht, The Netherlands: Springer;Dyck VA, Hendrichs J, Robinson AS 2005:601-626.

111. Hernández-Ortiz V, Bartolucci AF, Morales-Valles P, Frías D, Selivon D: Cryptic Species of the Anastrepha fraterculus Complex (Diptera: Tephritidae): A Multivariate Approach for the Recognition of South American Morphotypes. Ann Entomol Soc Am 2012, 105:305-318.

112. Selivon D, Perondini ALP, Morgante JS: Haldane's rule and other aspects of reproductive isolation observed in the Anastrepha fraterculus complex (Diptera: Tephritidae). Genet Mol Biol 1999, 22:507-510.

113. Rull J, Abraham S, Kovaleski A, Segura DF, Mendoza M, Liendo MC, Vera MT: Evolution of pre-zygotic and post-zygotic barriers to gene flow among three cryptic species within the Anastrepha fraterculus complex. Entomol Exp Appl 2013, 148:213-222.

114. Segura DF, Vera MT, Rull J, Wornoayporn V, Islam A, Robinson AS: Assortative mating among Anastrepha fraterculus (Diptera: Tephritidae) hybrids as a possible route to radiation of the fraterculus cryptic species complex. Biol J Linn Soc 2011, 102:346-354.

115. Klassen W, Curtis C: History of the sterile insect technique. In Sterile Insect Tech Princ Pract Area-Wide Integr Pest Manag. Dordrecht, The Netherlands: Springer;Dyck VA, Hendrichs J, Robinson AS 2005:

116. Glossary of Phytosanitary Terms 2013; International Standards for Phytosanitary Measures. [http://www.fao.org/docrep/w3587e/w3587e01. htm].

117. Vreysen MJB, Gerardo-Abaya J, Cayol JP: Lessons from Area-Wide Integrated Pest Management (AW-IPM) Programmes with an SIT Component: an FAO//IAEA Perspective. Area-Wide Control Insect Pests Springer; 2007, 723-744.

118. Dyck VA, Hendrichs J, Robinson AS: Sterile Insect Technique: Principles and Practice in Area-Wide Integrated Pest Management. Dordrect, Netherlands: Springer; 2006, 787.
119. Ito Y, Yamamura K: Role of Population and Behavioural Ecology in the Sterile Insect Technique. In Sterile Insect Tech Princ Pract Area-Wide Integr Pest Manag. Dordrecht, The Netherlands: Springer;Dyck VA, Hendrichs J, Robinson AS 2005:177-208.

120. Parker A: Mass-Rearing for Sterile Insect Technique. In Sterile Insect Tech Princ Pract Area-Wide Integr Pest Manag. Dordrecht, The Netherlands: Springer;Dyck VA, Hendrichs J, Robinson AS 2005:209-232.

121. Calkins CO, Parker AG: Sterile insect quality. In Sterile Insect Tech Princ Pract Area-Wide Integr Pest Manag. Dordrecht, The Netherlands: Springer;Dyck VA, Hendrichs J, Robinson AS 2005:269-296.

122. Dowell R V, Worley J, Gomes PJ: Sterile insect supply, emergence, and release. In Sterile Insect Tech Princ Pract Area-Wide Integr Pest Manag. Dordrecht, The Netherlands: Springer;Dyck VA, Hendrichs J, Robinson AS 2005:297-324.

123. Vreysen MJB: Monitoring sterile and wild insects in area-wide integrated pest management programmes. In Sterile Insect Tech Princ Pract Area-Wide Integr Pest Manag. Dordrecht, The Netherlands: Springer;Dyck VA, Hendrichs J, Robinson AS 2005:325-361.

124. Barclay HJ, Hargrove JW, Clift A, Meats A: Procedures for declaring pest free status. In Sterile Insect Tech Princ Pract Area-Wide Integr Pest Manag. Dordrecht, The Netherlands: Springer;Dyck VA, Hendrichs J, Robinson AS 2005:363-386.

125. Sarno F, Ruiz MF, Eirín-López JM, Perondini ALP, Selivon D, Sánchez L: The gene transformer-2 of Anastrepha fruit flies (Diptera, Tephritidae) and its evolution in insects. BMC Evol Biol 2010, 10:140.

126. Ruiz MF, Milano A, Salvemini M, Eirín-López JM, Perondini ALP, Selivon D, Polito C, Saccone G, Sánchez L: The gene transformer of Anastrepha fruit flies (Diptera, Tephritidae) and its evolution in insects. PLOSONE 2007, 2.

127. Sarno F, Ruiz MF, Sánchez L: Effect of the transformer-2 gene of Anastrepha on the somatic sexual development of Drosophila. Int J Dev Biol 2011, 55:975-979.

128. Ruiz MF, Stefani RN, Mascarenhas RO, Perondini ALP, Selivon D, Sánchez L: The gene doublesex of the fruit fly Anastrepha obliqua (Diptera, Tephritidae). Genetics 2005, 171:849-854.

129. Sánchez L: Sex-determining mechanisms in insects. Int J Dev Biol 2008, 52:837-856.

doi:10.1186/1471-2156-15-S2-S12

Cite this article as: Cladera et al:: Genetics and biology of Anastrepha fraterculus: research supporting the use of the sterile insect technique (SIT) to control this pest in Argentina. BMC Genetics 2014 15(Suppl 2):S12.

\section{Submit your next manuscript to BioMed Central and take full advantage of:}

- Convenient online submission

- Thorough peer review

- No space constraints or color figure charges

- Immediate publication on acceptance

- Inclusion in PubMed, CAS, Scopus and Google Scholar

- Research which is freely available for redistribution 